\title{
PROPER CONNECTION OF DIRECT PRODUCTS
}

\author{
RICHARD H. HAMMACK
}

AND

DeWEy T. TAYLOR

\author{
Department of Mathematics and Applied Mathematics \\ Virginia Commonwealth University \\ Richmond, VA 23284-2014, USA \\ e-mail: rhammack@vcu.edu \\ dttaylor2@vcu.edu
}

\begin{abstract}
The proper connection number of a graph is the least integer $k$ for which the graph has an edge coloring with $k$ colors, with the property that any two vertices are joined by a properly colored path. We prove that given two connected non-bipartite graphs, one of which is (vertex) 2-connected, the proper connection number of their direct product is 2 .
\end{abstract}

Keywords: direct product of graphs, proper connection of graphs.

2010 Mathematics Subject Classification: 05C38, 05C40, 05C76.

\section{REFERENCES}

[1] M. Basavaraju, S. Chandran, D. Rajendraprasad and A. Ramaswamy, Rainbow connection number of graph power and graph products, Graphs Combin. 30 (2014) 1363-1382.

doi:10.1007/s00373-013-1355-3

[2] V. Borozan, S. Fujita, A. Gerek, C. Magnant, Y. Manoussakis, L. Montero and Zs. Tuza, Proper connection of graphs, Discrete Math. 312 (2012) 2550-2560. doi:10.1016/j.disc.2011.09.003

[3] Y. Caro, A. Lev, Y. Roditty, Zs. Tuza and R. Yuster, On rainbow connection, Electron. J. Combin. 15 (2008) \#R 57.

[4] G. Chartrand, G. Johns, K. McKeon and P. Zhang, Rainbow connection in graphs, Math. Bohem. 133 (2008) 85-98. 
[5] D. Dellamonica Jr., C. Magnant and D. Martin, Rainbow paths, Discrete Math. 310 (2010) 774-781.

doi:10.1016/j.disc.2009.09.010

[6] A. Gerek, S. Fujita and C. Magnant, Proper connection with many colors, J. Comb. 3 (2012) 683-693.

doi:10.4310/JOC.2012.v3.n4.a6

[7] R. Hammack, W. Imrich and S. Klavžar, Handbook of Product Graphs, Second Edition (Series: Discrete Mathematis and its Applications, CRC Press, 2011).

[8] Y. Moa, F. Yanling, Z. Wang and C. Ye, Proper connection number of graph products, (2015). arXiv:1505.02246

[9] D. West, Introduction to Graph Theory, Second Edition (Prentice Hall, Inc., Upper Saddle River, NJ, 2001).

[10] H. Whitney, Non-separable and planar graphs, Trans. Amer. Math. Soc. 34 (1932) 339-362.

doi:10.1090/S0002-9947-1932-1501641-2

Received 19 March 2016

Revised 8 June 2016

Accepted 22 August 2016 